UDC 378.316

LBC 88.5

\title{
APPLYING A SYSTEMATIC APPROACH TO THE DEVELOPMENT OF FUNDAMENTAL ACMEOLOGY
}

\author{
Aleksey F. Rodyukov \\ Saint Petersburg State University of Telecommunications named after Prof. M.A. Bonch-Bruevich, \\ Saint Petersburg, Russian Federation
}

\begin{abstract}
St.-Petersburg's school of acmeology has gone the way of fruitful development from the original understanding of its subject field as a psychological discipline to its foundation as a fundamental science. On the basis of the dialectical and synergistic replenishment of its central notion "acme" with the polar notion of "kate" acmeology expanded not only due to a new direction - katabology but it also obtained the benefits of dialectical completeness. Instead of a temporary alternation of anabolic and catabolic poles there comes understanding of their penetration into each other, like any other "pair" of dialectical oppositions. As S.D. Pozharsky puts it, acmeology describes development as an alternation of ascents and slumps, the ascending line and descending line, progress and regress. However, it isn't possible to have an adequate description of the development only by the alternation of higher stages of maturity (acme) and its low-lying phases (kate). Overcoming such a theoretical "circle" requires the consideration of the problem in the context of the methodological paradigm of structural-functional approach. This allows us to reveal own influence of the acme point on the qualitative changes in various types of structures. We formulate a conclusion that the degree of influence of the acme point on its subsystems is a measure (criterion) of the level of Acme itself that is everything that is applied to a wide range of objects.
\end{abstract}

Key words: acmeology, acme, kate, inter-pole space of dual oppositions, inversion.

УДК 378.316

ББК 88.5

\section{ПРИМЕНЕНИЕ СИСТЕМНОГО ПОДХОДА К РАЗРАБОТКЕ ФУНДАМЕНТАЛЬНОЙ АКМЕОЛОГИИ}

\author{
Алексей Федорович Родюков \\ Санкт-Петербургский государственный университет телекоммуникаций им. проф. М.А. Бонч-Бруевича, \\ г. Санкт-Петербург, Российская Федерация
}

\begin{abstract}
Аннотация. Отталкиваясь от античной традиции, Санкт-Петербургская школа акмеологии прошла путь плодотворного развития от первоначального осмысления своего предметного поля в качестве психологической дисциплины до ее становления в качестве фундаментальной науки. На базе диалектико-синергетического восполнения ее центрального понятия «акме» полярным понятием «кате» акмеология не только расширилась за счет нового направления исследования - катабологии, но и обрела преимущества диалектической полноты. Основным результатом явилось глубокое осмысление диалектики межполюсного пространства исходных понятий теории и его заполнение рядом модификаций, а также обращение к более широкому _ кругу объектов теории. На место временному чередованию анаболических и катаболических полюсов пришло понимание их взаимопроникновения друг в друга, подобно любым другим «парным» диалектическим противоположностям. Согласно С.Д. Пожарскому, акмеология описывает развитие как чередование подъемов и спадов, восходящей и нисходящей линий, прогресса и регресса. Однако невозможно адекватное описание развития лишь чередованием высших этапов зрелости (акме) и его низинных этапов (кате). Необходимо преодолеть такую «игру в бисер» (В.П. Бранский) подобных бесплодных чередований. Преодоление теоре궁 тическог «круга» требует рассмотрения проблемы в контексте методологической парадигмы структурнофункционального подхода. Это позволяет выявить собственное влияние точки акме на качественные изме-
\end{abstract}


нения различного рода структур. Формулируется вывод, согласно которому степень влияния точки акме на свои подсистемы является мерилом (критерием) уровня самого акме как такового, то есть ко всему, что приложимо к широкому кругу объектов.

Ключевые слова: акмеология, акме, кате, межполюсное пространство дуальных оппозиций, инверсия.

Предлагаемая статья имеет одновременно обзорный и проблемный характер, поскольку, исходя из достигнутого отечественной акмеологией уровня, становятся виднее ее недоработки. Последние связаны как с определенной неполнотой теории, так и с не проясненной проблемой влияния собственного значения «точки» акме на порождающие эти «точки» основания. Согласно С.Д. Пожарскому, акмеология описывает развитие как чередование подъемов и спадов, восходящей и нисходящей линий, прогресса и регресса $[10$, с. 8$]$. Однако невозможно адекватное описание развития лишь чередованием высших этапов зрелости (акме) и низинных этапов (кате). Необходимо преодолеть такую «игру в бисер» (В.П. Бранский) бесплодных чередований вершин и низин развития. Для этого нужно выработать сам критерий значения «точки» акме по отношению к собственным основаниям ее расцвета.

Для обоснования данного положения необходимо обращение к системному подходу. Он позволяет представить анаболический процесс и его высший результат не просто как движение к точке акме и «попятное» движение к кате, а как процесс, ведущий к перестройке всей конкретной системы, и ее «подтягивание» к высшему, более совершенному состоянию. Причем такое «подтягивание» можно фигурально сопоставить с понятием аттрактора, способностью перестраивать систему оптимальным образом. Это означает, что речь идет о качественном изменении и развитии всей данной системы.

В этом и состоит подлинный смысл акме, а не только в том, что расцвет чего-либо сменяется его закатом.

Становление и дальнейшее развитие акмеологии базируется на основательном историко-философском фундаменте, традиционной диалектике и научной синергетике. Она отражает разные уровни бытия (природы, социокультурных сообществ, творческого самосовершенствования человека - этического, эстетического и аксиологического), взятые в аспекте отбора наилучшего, выявления выдающихся результатов совершенствования в каждой из этих сфер. Однако, «несмотря на то, что предпосылки акмеологии уходят корнями в натурфилософские концепции античности, статус науки она приобрела только в первой половине XX в.» [10, с. 7].

Начальный этап был связан с трудами Н.А. Рыбникова и Б.Г. Ананьева, с изучением различий особенностей развития в детстве и в зрелом возрасте человека, конкретизацией фаз его активного развития. Поэтому проистекало психологическое представление о предмете акмеологии как науке, изучающей «феноменологию, закономерности и механизмы развития человека на ступени его взрослости и особенно при достижении им наиболее высокого уровня в этом развитии» [2, с. 7]. В то же время продолжающиеся дискуссии указывают на то, что она переросла себя как преимущественно психологическая дисциплина. Произошла дальнейшая разработка акмеологии как одной из составляющих наук о предельно общих законах и закономерностях достижения результата в развитии систем и структур различной природы. На этом пути важнейшим моментом стала разработка новаторской идеи В.П. Бранского о дополнении акмеологии учением о низинных этапах развития (катабология) [3, с. 88] в рамках теории социальной самоорганизации. Была показана связь основных понятий научной синергетики - порядка и хаоса - с понятиями акме и кате, а также прогресса и регресса, поскольку кате обладает, подобно хаосу, потенциальной творческой силой [10, с. 37]. Межполюсное пространство оппозиции вершинности и низинности было заполнено рядом дополнительных терминов («апротазис», «протазис», «эпитазис», «катастазис», «катастрофе», «катаболе», «неоапротазис»). А взаимосвязь акме и кате была переосмыслена как их одновременное сосуществование и нераздельность во времени и пространстве $[10$, с. $35-$ 36]. Тем самым, согласно «закону вершинности», без изменения и обновления мы не мо- 
жем говорить о развитии объектов и явлений любого уровня» [9, с. 226].

Как видно из приведенного обзора достижений фундаментальной акмеологии, поставленная в начале статьи проблема пока не находит решения.

Недаром говорится, что исходные понятия являются лишь заветной конечной целью гуманитарного знания $[1$, с. 8$]$ и решения его проблем. Для этого недостаточно использования только общих принципов научного мировоззрения $[10$, с. 12$]$ (объективности, наблюдаемости, детерминизма, рациональности, эмпирической проверяемости и др.). Необходимо обращение к структурно-функциональному подходу. Тогда акмеология покинет свою преимущественно валюативную (ценностную, ориентированную на должное) основу и более прочно встанет на почву рефлективной (ориентированной на сущее) науки. Для продолжения уже начатого необходимо обращение к иным, ранее не использованным в акмеологии принципам исследования.

Принцип взаимосвязи и инверсии порядка и хаоса; принцип разрешения противоречий на уровне общего (всеобщего); принцип обратной связи (системы и ее окружения); принципы нелинейности и необратимости, координации и субординации, иерархизации и деиерархизации; принцип несводимости целого к сумме его частей; принцип соотношения организации и самоорганизации, выбора и отбора, свободы и ответственности и др. По понятным причинам мы ограничимся лишь некоторыми приложениями к ним.

В частности, речь идет о том новом, что возникает в отношении к предыдущим этапам формирования, и того нового, которое достигнуто в преобразовании системы, а следовательно, качественного изменения всей конкретной структуры отношений в исследуемой сфере. При этом мы исходим из признания того, что подобного рода процессы и результаты обнаруживаются на уровне индивида, группы, института, общества в целом и его подсистем.

Так, с этих позиций акме выдающейся личности связано не только с прохождением ею ряда «ступеней» саморазвития или воздействием на ее формирование соответствующего окружения - акмеологического (конструк- тивного, творческого) или катаболического (деструктивного, преступного). Путь личностного интимного самосовершенствования может носить неявный, замкнутый на себя характер, и до поры никак не влиять на других людей, их группы, организации и пр. Результат объективируется лишь при условии сопоставления проявленного результата саморазвития данного индивида по отношению достигнутой «вершины» к тому или иному «низу». Оценка по оси «снизу вверх» сменяется оценкой «сверху вниз». Происходит переворот, инверсия всего отношения: «верх» (акме) «определяет» «низ» как «подножие», от которого начинается сам подъем. Пройденные при этом в результате подъема ступени роста, вместо «постава» (способа выхода из потаенности по Хайдеггеру) становятся «подсистемой» по отношению к новому достигнутому статусу «вершины».

С вершины достигнутого великой личности становится легче управлять, руководить теми или иными сферами жизни, причем достигнутый авторитет продолжает свое действие и после кончины гения эпохи. Такой гений сам становится высшим «проектом» того целого, из которого он сам произрастал. Из части он становится целым, началом преобразования и самосовершенствования «других». Так, гений А.С. Пушкина возрос до уровня «духовно национального проекта», определяющего до сих пор многие подструктуры культурного горизонта России и как бы руководя ими. Его гений расцвел до масштабов целостной сферы, или, точнее, сверхсистемы ценностей, он трансформируется в «эстетосферу», подчиняя уже самому себе все собственные подсистемы, становясь их «руководящим принципом».

При этом становление гения не обходится без отбора среди других претендентов, способствуя появлению высшего (акмеологического) лидера. А стремление «подтянуться〉 до него ведет к появлению в социокультурной среде большего многообразия, интегрированного во все большей степени, что, несомненно, связано с формированием среды (окружением) развития и конвергенции. Таким образом, отбор является неотъемлемой стороной процесса возникновения высшего из низшего и их взаимодействия. Причем функционирование данных противоположностей 
направлено на превращение «своего другого» в условие собственного развития [5, с. 125127]. Очевидно, что учет достижений теории отбора необходим при рассмотрении конкретно-всеобщей проблематики акмеологии.

Во всемирно-историческом масштабе анаболический рост цивилизации соединяет наличие сильного коллективного сознания с наличием сильной личности. А потому, согласно Э. Дюркгейму, можно видеть из установления деспотической власти первый шаг на пути индивидуализма, а не только умаление личности. У вождей открывается источник инициативы, который ранее не существовал. Только они могли противопоставить свое мнение воле коллектива. Поэтому объяснение социальной роли управляющих, их силу и влияние надо искать (как это ни парадоксально) не в их личных качествах, а в природе управляемых. Вождизм оборачивается первоначальной формой становления личности человека. Но для того, чтобы увеличилась свобода большинства или всех личностей, нужно (хотя и этого недостаточно), чтобы индивидуальное сознание стало более зрелым [11]. «Свобода имеет существенные онтологические основания - наличие отбора и суперотбора. “Играя роль” отбора, человек осуществляет суперотбор, то есть отбор самих факторов отбора, руководствуясь истиной или идеалом, в целях упрощения или, наоборот, усложнения ситуации» [4, с. 39]. Должны расшириться социальные функции индивидуального фактора, его удельный вес относительно других частей социального целого [6, с. 133].

Ускоренный рост свободы каждого индивида становится условием «свободного развития всех» (К. Маркс), а проблема свободы переводится с индивидуального уровня рассмотрения на социально-эволюционный уровень теоретического обобщения.

На ином уровне функционирования общества сходные процессы все более явно обнаруживают себя в рамках глобализации и информатизации человечества. Происходит стремительное расширение масштабов коммуникации, при котором новейшие технологии делают возможным общение представителей разных культур и цивилизаций. Данные процессы однозначно характеризуются массо- вым сознанием в терминах акмеологического самосовершенствования, позитивности и комфортности. При этом развитие инфокоммуникационной сферы оборачивается перестройкой прежнего системного единства, формированием новой мировой культуры и всей архитектоники мирового сообщества. Данные процессы, - отмечает В.В. Миронов, - «разрушая классическую систему цивилизации как совокупности локальных культур, локальных государств... может реализоваться как наднациональное управление миром и вернуть нас на новой ступени к некой Глобальной Империи...»» [8, с. 10]. То есть это новое глобальное целое будет придавать новое системное качество всем локальным культурам. Это качество будет присуще всем культурам в рамках целостности и будет отсутствовать у отдельно взятой локальной культуры. Не вдаваясь в рассмотрение негативных тенденций развития, связанных с глобализацией и инфокоммуникацией современного мира, отметим фундаментальный сдвиг в соотношении прежнего и нового этапа информатизации.

И здесь происходит нечто принципиально сходное с процессами глобализации. Оно обнаруживает себя в развитии информации, точнее, в движении во всемирном масштабе от подсистемного, подчиненного, обслуживающего и локального характера информационных технологий к формированию глобальной (нелокальной) мировой Информационной Сферы (как конкретного результата формирующейся ноосферы В.И. Вернадского). Ранее связанные друг с другом локальные подсистемы, вынуждены теперь «работать» по законам новой, тотальной «вершины», каковой на наших глазах становится глобальная коммуникация [8, с. 10]. На место «горизонтальных» связей между подсистемами нарастает, как снежный ком, новая глобальная информационная суперсистема. Более того, она подчиняет себе уже не только собственные подсистемы, но и те социальные сферы, которые сами по себе не обладают информационными функциями.

Акмеологическая оценка современного состояния инфосферы и массмедиа напрямую связана с их обособлением как от остальных функциональных систем, к числу которых относятся экономика, политика, искусство, пра- 
во, наука и др., так и от психических систем индивидов [12; 13]. Посредством различения информативных и неинформативных сообщений, распределения их по программным областям (новости, реклама, развлечения) и порождения конкретных тем коммуникации и современные «массмедиа конструируют реальность [7, с. 17].

Рассмотренные примеры говорят о том, как в таких «подтягиваниях» обратная связь с акме оборачивается качественным влиянием на любые системы, классы и индивиды, будь то стиль жизни людей, их ментальность, искусство, наука и т. д. Таким образом, речь уже идет не о простом воспроизводстве системы самой себя, но и о ее качественном изменении.

Так, монах-отшельник, проходя сложный путь самосовершенствования, становится в его результате святым, точкой притяжения для множества других людей и необязательно лишь для подвижников веры.

Обобщение подобных процессов позволяет сформулировать нетривиальный вывод, согласно которому степень влияния точки акме на свои подсистемы является мерилом (критерием) уровня самого акме как такового, будь это отдельный индивид, группа, институт, организация, общество или человечество в целом.

\section{СПИСОК ЛИТЕРАТУРЫ}

1. Бахтин, Л. М. Индивидуальность и личность в истории (дискуссия) /Л. М. Бахтин // Одиссей. Человек в истории. Личность и общество. - М. : Наука, 1990. - 222 с.- С. 6-8.

2. Бодалев, А. А. Акмеология. Настоящий человек. Каков он и как им становятся? / А. А. Бодалев, Н. В. Васина. - СПб. : Речь, 2010. - 224 с.

3. Бранский, В. П. Социальная синергетика и акмеология / В. П. Бранский, С. Д. Пожарский. СПб. : Политехника, 2001. - 159 с.

4. Бусов, С. В. Проблематика свободы и выбора в истории философии и социальной практики / С. В. Бусов // Вестник Пермского университета. Серия: Философия. Психология. Социология. 2014. - Вып. 2 (14). - С. 31-40.

5. Внутских, А. Ю. Отбор в природе и отбор в обществе: опыт конкретно-всеобщей теории / А. Ю. Внутских. - Пермь : Изд-во Перм. госун-та, 2006. $-335 \mathrm{c}$.
6. Дюркгейм, Э. О разделении общественного труда / Э. Дюркгейм ; пер. с фр. А. Б. Гофман. М. : Наука, 1991. -527 с.

7. Луман, Н. Общество как социальная система / Н. Луман ; пер. с нем. А. Антоновский. - М. : Логос, 2004. - 232 c.

8. Миронов, В. В. Глобализация и угрозы унификации / В. В. Миронов // Философские искания: Московско-Петербургский сборник / под ред. В. В. Миронова. - Вып. 2. - М. : Изд-во Моск. ун-та, 2011.-C. 7-26.

9. Пожарский, С. Д. Акмеология и катабология: теория совершенствования человека / С. Д. Пожарский. - СПб. : ЛЕМА, 2013. - 266 с.

10. Становление фундаментальной акмеологии / под ред. С. Д. Пожарского. - СПб. : ЛЕМА, 2015. $-174 \mathrm{c}$.

11. Durkheim, E. The Rules of Sociological Method: and Selected Texts on Sociology and its Method / ed. by S. Lukas. - London : Palgrave Macmillan, 2013.-272 p.

12. Luhmann, N. Social Systems / N. Luhmann. Stanford : Standford University Press, 1995. - 627 p.

13. Luhmann, N. The World Society as a Social System / N. Luhmann // International Journal of General Systems. - 1982. - Vol. 8, no. 1. - P. 131-138.

\section{REFERENCES}

1. Bakhtin L.M. Individualnost $\mathrm{i}$ lichnost v istorii (diskussiya) [The Individuality and Personality in the History(Debate)]. Odissey. Chelovek v istorii. Lichnost $i$ obshchestvo [Odysseus. Man in History. The Individual and Society]. Moscow, Nauka Publ., 1990, pp. 6-8.

2. Bodalev A.A., Vasina N.V. Akmeologiya. Nastoyashchiy chelovek. Kakov on i kak im stanovyatsya? [Akmeology. Real Man. What is He and How to Become Him?]. Saint Petersburg, Rech Publ., 2010. 224 p.

3. Branskiy V.P., Pozharskiy S.D. Sotsialnaya sinergetika i akmeologiya [Social Synergetics and Acmeology]. Saint Petersburg, Politekhnika Publ., 2001. 159 p.

4. Busov S.V. Problematika svobody i vybora v istorii filosofii i sotsialnoy praktiki [The Issue of Freedom and Choice in the History of Philosophy and Social Practice]. Vestnik Permskogo universiteta. Seriya: Filosofiya. Psikhologiya. Sotsiologiya, 2014, vol. 2 (14), pp. 31-40.

5. Vnutskikh A.U. Otbor v prirode $i$ otbor $v$ obshchestve: opyt konkretno-vseobshchey teorii [The Selection in Nature and Selection in Society: the Experience of a Concrete - Universal Theory]. Perm, Izd-vo Permskogo gosuniversiteta, 2006. $335 \mathrm{p}$. 
6. Durkheim E. Orazdelenii obshchestvennogo truda [On Public Labour Division]. Moscow, Nauka Publ., 1991. $527 \mathrm{p}$.

7. Luhmann N. Obshchestvo kak sotsialnaya sistema [Society as a Social System]. Moscow, Logos Publ., 2004. 232 p.

8. MironovV.V. Globalizatsiya i ugrozy unifikatsii [Globalisation and the Threats of Unification]. Filosofskie iskaniya: Moskovsko-Peterburgskiy sbornik [Philosophical Inquiry: Moscow-St. Petersburg Collection]. Moscow, Izd-vo Moskovskogo universiteta, 2011, iss. 2, pp. 7-26.

9. Pozharskiy S.D. Akmeologiya i katabologiya: teoriya sovershenstvovaniya cheloveka [Acmeology and Katabology: the Theory of Human Perfection]. Saint Petersburg, LEMA Publ., 2013. 266 p.

10. Pozharskiy S.D., ed. Stanovleniye fundamentalnoy akmeologii. Kollektivnaya monografiya [Formation of the Fundamental Acmeology. Collective Monograph]. Saint Petersburg, LEMA Publ., 2015. 174 p.

11. Durkheim E. The Rules of Sociological Method: and Selected Texts on Sociology and its Method. London, Palgrave Macmillan, 2013. 272 p.

12. Luhmann N.. Social Systems. Stanford. Standford University Press, $1995.627 \mathrm{p}$.

13. Luhmann N. The World Society as a Social System. International Journal of General Systems, 1982, vol. 8, no.1, pp.131-138.

\section{Information about the Author}

Aleksey F. Rodyukov, Candidate of Philosophical Sciences, Associate Professor, Department of Social and Political Sciences, Saint Petersburg State University of Telecommunications named after Prof. M.A. Bonch-Bruevich, Prosp. Bolshevikov, 22, 193232 Saint Petersburg, Russian Federation, a.rodukov@yandex.ru.

\section{Информация об авторе}

Алексей Федорович Родюков, кандидат философских наук, доцент кафедры социальнополитических наук, Санкт-Петербургский государственный университет телекоммуникаций им. проф. М.А. Бонч-Бруевича, просп. Большевиков, 22, 193232 г. Санкт-Петербург, Российская Федерация, a.rodukov@yandex.ru. 